J. Bangladesh Acad. Sci., Vol. 42, No. 2, 171-176, 2018

DOI: https://doi.org/10.3329/jbas.v42i2.40049

\title{
MEASUREMENT OF RADIOACTIVITY AND ASSESSMENT OF RADIOLOGICAL HAZARD OF TEA SAMPLES COLLECTED FROM LOCAL MARKET IN BANGLADESH
}

\author{
MST. NAJNIN AKTAR ${ }^{1}$, SURANJAN KUMAR DAS ${ }^{* 1}$, SELINA YEASMIN ${ }^{2}$, M. M. MAHFUZ SIRAZ ${ }^{2}$ \\ AND A. F. M. MIZANUR RAHMAN ${ }^{3}$
}

Department of Physics, Jagannath University, Dhaka, Bangladesh

\begin{abstract}
The activity concentrations of natural radionuclides and radiological hazard indices in eleven tea samples collected from local market in Bangladesh have been analyzed by using High Purity Germanium (HPGe) Detector. The average activity concentrations of ${ }^{226} \mathrm{Ra},{ }^{232} \mathrm{Th}$ and ${ }^{40} \mathrm{~K}$ in tea samples have been found to be $21.21 \pm 14.04,32.43 \pm 7.48$ and $93.47 \pm 43.94 \mathrm{Bqkg}^{-1}$ respectively. The calculated absorbed dose rates due to these radioactive nuclides in tea samples have been found to vary from $26.24 \mathrm{nGyh}^{-1}$ to $37.95 \mathrm{nGyh}^{-1}$ and average value was $33.28 \mathrm{nGyh}^{-1}$. The estimated outdoor annual effective dose rates varied from $38.64 \mu \mathrm{Svy}^{-1}$ to 55.89 $\mu \mathrm{Svy}^{-1}$ with the mean value of $49.02 \mu \mathrm{Svy}^{-1}$ which is less than the world average value of $1000 \mu \mathrm{Svy}^{-1}$. The values of radium equivalent activity in all samples are less than the permissible maximum value of the radium equivalent activity which is $370 \mathrm{Bqkg}^{-1}$ according to UNSCEAR 2000 report. The values of external and internal hazard indices for different samples varied from 0.16 to 0.23 with the average value of 0.20 and from 0.21 to 0.29 with an average of 0.26 . The value of this index must be less than unity in order to keep the radiation hazard insignificant. It was also found that there is no artificial radionuclide (for example ${ }^{137} \mathrm{Cs}$ ) in any of the samples. The data generated in this study will provide baseline radiometric values for natural and artificial radioactivity in tea samples in Bangladesh.
\end{abstract}

Key words: Radioactivity, High purity germanium detector, Tea sample, Radiological indices.

\section{INTRODUCTION}

Radioactive materials are present naturally throughout the environment. It exists in soil, rocks, plants, sand, water and air. These radioactive materials come from the floor and walls of our homes, food we eat and drink and the air we breathe. The natural radioactivity in the environment is the main source of radiation exposure for human being. Around $80 \%$ radioactivity comes from natural sources (UNSCEAR 2008 report). Natural radionuclide assigns a significant amount of background radiation exposure to the population through inhalation and ingestion (Miah et al. 2012). Besides natural sources, artificial radioactive elements in the environment come from various man made sources. The aim of this study is to determine the radioactivity levels and

*Corresponding author: <skdas@phy.jnu.ac.bd>.

${ }^{1}$ Department of Physics, Jagannath University, Dhaka-1100. Bangladesh.

${ }^{2}$ Health Physics Division, Atomic Energy Centre, Dhaka, Bangladesh.

${ }^{3}$ Nuclear Power and Energy Division, Bangladesh Atomic Energy Commission radionuclides in the tea samples for assessing the effects of radiation exposure due to both natural and artificial radioactivity. Tea is a popular drink in our country and abroad which is prepared from the leaves of a shrub Camellia sinensis. About 18-20 billion tea cups are consumed daily in the world for economic, social interest and refreshment (Pedro et al. 2001). Tea plants may be subjected to direct and indirect contamination of various radionuclides, such as ${ }^{226} \mathrm{Ra},{ }^{232} \mathrm{Th}$ and ${ }^{40} \mathrm{~K}$. These radionuclides can be distributed in different parts of the plants according to the chemical characteristics and parameters of the plants and soil. It is crucial to estimate the ingestion dose to the public. The ingestion dose above permissible level is very harmful for human being (Khatun et al. 2013). In this study, 
the activity concentrations of natural $\left({ }^{226} \mathrm{Ra}\right.$, ${ }^{232} \mathrm{Th}$ and ${ }^{40} \mathrm{~K}$ ) and artificial (for example ${ }^{137} \mathrm{Cs}$ ) radionuclides were determined in collected tea samples by using High purity Germanium detector (HPGe). The aim of this research work is not only the determination of radioactive nuclides in tea samples but also the determination of the radiological hazard parameters such as Absorbed dose rate, Radium equivalent activity, External hazard index, Annual effective dose for individual living being. Another aim of the present work is to create the public awareness about the radiation hazards. This study will also be helpful to establish a base line data for future guidelines in Bangladesh.

\section{MATERIALS AND METHODS}

Eleven samples of different brands of tea have been collected from the local market in Bangladesh (Dhaka city) during the year of the experiment. Upon collection, all the samples were properly packed in cylindrical plastic containers of $7 \mathrm{~cm}$ height and $5.5 \mathrm{~cm}$ in diameter. The sample-filled plastic containers were sealed tightly with cap and wrapped with thick vinyl tape around their necks; marked individually with identification number and date of preparation and net weight of the samples. The samples were then transported, stored and processed at the sample preparation laboratory of Atomic Energy Center, Dhaka. After then samples were stored for about 30 days to ensure secular equilibrium between ${ }^{238} \mathrm{U}$ and ${ }^{232} \mathrm{Th}$ series and their daughter progenies.

\section{Gamma spectroscopy and analysis}

High purity germanium detector is used without any added impurity. It consists of a cylindershaped n-type germanium crystal. The detection and measurement of radionuclides in the samples were carried out by gamma spectrometry system using a p-type co-axial HPGe detector of $93 \mathrm{~cm}^{3}$ active volume and $20 \%$ relative efficiency supplied by CANBERRA (Model GC-2018 and serial No. 0408941). The co-axial geometry with electrical contacts in the form of concentric cylinders closed at the end makes it possible to produce very large volume detector elements with excellent efficiencies for high-energy photons.

The resolution of HPGe detector was of $2 \mathrm{keV}$ at $1332 \mathrm{keV}$ of Cobalt-60 gamma-ray line. $16 \mathrm{k}$ channel analyser was used with the detector. The spectra of all samples were perfectly analysed by using Genie-2000 spectra analysis software to calculate the concentrations of ${ }^{226} \mathrm{Ra},{ }^{232} \mathrm{Th}$ and ${ }^{40} \mathrm{~K}$ (Ahmed et al. 2014). All the samples were counted for 5000s. The equal counting time for background and sample measurement was chosen to minimize the uncertainty in the net counts. The spectrum of each sample was analyzed. The centroid energies of the peaks from the spectrum were compared with the reference gamma-ray energies obtained from the literature. Measured activity concentration of ${ }^{226} \mathrm{Ra}$ and ${ }^{232} \mathrm{Th}$ from their daughter nuclides which consist of daughter nuclides $\left[{ }^{214} \mathrm{~Pb}(295.2\right.$ $\mathrm{keV}),{ }^{214} \mathrm{~Pb}(351.9 \mathrm{keV}),{ }^{214} \mathrm{Bi}(609.3 \mathrm{keV}),{ }^{214} \mathrm{Bi}$ $\left.(1120.2 \mathrm{keV}),{ }^{214} \mathrm{Bi}(1764.4 \mathrm{keV})\right]$ and $\left[{ }^{212} \mathrm{~Pb}\right.$ (238.6 keV), ${ }^{208} \mathrm{Tl}(583.1 \mathrm{keV}),{ }^{228} \mathrm{Ac}(911.2$ $\left.\mathrm{keV}),{ }^{228} \mathrm{Ac}(968.9 \mathrm{keV})\right]$ respectively were recorded. The activity concentration values quoted assume secular equilibrium for the different isotopic activities in decay chains. The activity concentrations of ${ }^{40} \mathrm{~K}$ were determined directly by measurement of the gamma-ray transitions at $1460.8 \mathrm{keV}$. No artificial radionuclide was found in the measurement.

In the present study, 10 transitions of gamma ray lines of the radionuclide ${ }^{152} \mathrm{Eu}$ were used to perform the efficiency calibration. The energy calibration of the detector was performed by ${ }^{137} \mathrm{Cs}$ and ${ }^{60} \mathrm{Co}$ point sources. 
The radioactivity of each sample was measured using the calibrated high purity germanium detector. The activity concentration of each radionuclide in the sample was determined by using the net count rates (cps) for the same counting time under the selected photo peaks, weight of the sample, the photo peak efficiency, and the gamma intensity at a specific energy as given by the following equation (Knoll, 1998).

$$
A=\frac{N \times 100 \times 1000}{P_{\gamma} \times \varepsilon \times W}
$$

where,

$N=$ Net counts per second (c.p.s) $=$ (Sample c.p.s) - (Background c.p.s)

$P \gamma=$ Transition probability of gamma ray

$\Xi=$ Efficiency in percent

$W=$ Weight of the sample in gm The errors in the measurement have been expressed in terms of standard deviation

$$
\sigma=\left[\frac{N_{s}}{T_{s}^{2}}+\frac{N_{b}}{T_{b}^{2}}\right]^{\frac{1}{2}}
$$

where, $N_{s}$ is the sample counts measured in time $T_{s}$ and $N_{b}$ is the background counts measured in time $T_{b}$. The standard deviation in cps was converted into activity in $\mathrm{Bqkg}^{-1}$.

\section{Calculation of radiological hazard}

A direct connection between the radioactivity concentrations of natural radionuclides and their exposure is known as the absorbed dose rate. The mean activity concentrations of ${ }^{226} \mathrm{Ra},{ }^{232} \mathrm{Th}$, and ${ }^{40} \mathrm{~K}\left(\mathrm{~Bq} \cdot \mathrm{kg}^{-1}\right)$ in the given samples at $1 \mathrm{~m}$ above the ground surface was calculated using the formula (UNSCEAR, 2008):

$\mathrm{D}\left(\mathrm{nGy} \cdot \mathrm{h}^{-1}\right)=0.462 \mathrm{C}_{\mathrm{Ra}}+0.604 \mathrm{C}_{\mathrm{Th}}+0.0417 \mathrm{C}_{\mathrm{K}}$ where, D is the absorbed dose rate in nGy. $\mathrm{h}^{-1}$, $\mathrm{C}_{\mathrm{Ra}}, \mathrm{C}_{\mathrm{Th}}$ and $\mathrm{C}_{\mathrm{K}}$ are the activity concentration of ${ }^{226} \mathrm{Ra},{ }^{232} \mathrm{Th}$ and ${ }^{40} \mathrm{~K}$ respectively.

The annual effective dose equivalent can be estimated using the following formula

$D_{\text {eff }}\left(\mu\right.$ Sv $\left.\cdot y^{-1}\right)=D\left(n G y \cdot h^{-1}\right) \times 8766 h \times$

$0.2 \times 0.7 \mathrm{~Sv} . \mathrm{Gy}^{-1} \times 10^{-3}$

By using a conversion factor of 0.7 Sv. Gy ${ }^{-1}$, which converts the absorbed dose rate in air to human effective dose and 0.2 for the outdoor occupancy factor proposed by the UNSCEAR 2000 report were used.

Due to a non-uniform distribution of natural radionuclides, the actual activity level of ${ }^{226} \mathrm{Ra}$, ${ }^{232} \mathrm{Th}$ and ${ }^{40} \mathrm{~K}$ in the samples can be evaluated by means of a common radiological index as radium equivalent activity $\left(\mathrm{Ra}_{\mathrm{eq}}\right)$. The specific activity of materials containing different amounts of ${ }^{226} \mathrm{Ra},{ }^{232} \mathrm{Th}$ and ${ }^{40} \mathrm{~K}$ according to Beretka and Mathew (Beretka, 1985) was calculated.

$\mathrm{Ra}_{\mathrm{eq}}\left(\mathrm{Bq} \cdot \mathrm{kg}^{-1}\right)=\mathrm{C}_{\mathrm{Ra}}+1.43 \mathrm{C}_{\mathrm{Th}}+0.077 \mathrm{C}_{\mathrm{k}}$

where $\mathrm{C}_{\mathrm{Ra}}, \mathrm{C}_{\mathrm{Th}}$ and $\mathrm{C}_{\mathrm{K}}$ are the activity concentrations of ${ }^{226} \mathrm{Ra},{ }^{232} \mathrm{Th}$ and ${ }^{40} \mathrm{~K}$ in Bq. $\mathrm{kg}^{-1}$, respectively. The permissible maximum value of the radium equivalent activity is $370 \mathrm{~Bq} \cdot \mathrm{kg}^{-1}$.

To limit the radiation exposure attributable to natural radionuclides in the samples to the permissible dose equivalent limit of $1 \mathrm{mSv}^{-1} \mathrm{y}^{-1}$, the external hazard index based on a criterion have been introduced using a model proposed by Krieger (1981) which is given by (Belivermis, 2010) :

$\mathrm{H}_{\mathrm{ex}}=\left(\mathrm{C}_{\mathrm{Ra}} / 370\right)+\left(\mathrm{C}_{\mathrm{Th}} / 259\right)+\left(\mathrm{C}_{\mathrm{K}} / 4810\right)$

In order to keep the radiation hazard insignificant, the value of external hazard index must not exceed the limit of unity. 


\section{RESULTS AND DISCUSSION}

The obtained activity concentration of natural radionuclides ${ }^{226} \mathrm{Ra},{ }^{232} \mathrm{Th}$ and ${ }^{40} \mathrm{~K}$ in tea samples collected from local market in Bangladesh are shown in Table 1.
$\mathrm{Bq} / \mathrm{kg}$ (UNSCEAR 2000). The obtained values are less than the acceptable level.

The activity concentration of the ${ }^{40} \mathrm{~K}$ in tea samples varied from $86.39 \pm 40.53 \mathrm{Bqkg}^{-1}$ to $102.07 \pm 47.98 \mathrm{Bqkg}^{-1}$ with an average value of

Table 1. The activity concentrations of ${ }^{226} \mathrm{Ra}^{232}{ }^{23}$ and ${ }^{40} \mathrm{~K}$ in tea samples $\left(\mathrm{Bqkg}^{-1}\right)$.

\begin{tabular}{lccc}
\hline Sample ID & ${ }^{226} \mathbf{R a}\left(\mathbf{B q k g} \mathbf{- 1}^{-1}\right)$ & ${ }^{{ }^{332}} \mathbf{T h}\left(\mathbf{B q k g}^{-1}\right)$ & ${ }^{40} \mathbf{K}\left(\mathbf{B q k g}{ }^{-1}\right)$ \\
\hline \hline Tea-1 & $19.53 \pm 13.40$ & $33.21 \pm 6.91$ & $89.57 \pm 41.99$ \\
Tea-2 & $20.78 \pm 14.16$ & $34.93 \pm 7.30$ & $93.28 \pm 44.35$ \\
Tea-3 & $23.31 \pm 15.33$ & $37.95 \pm 7.90$ & $102.07 \pm 47.98$ \\
Tea-4 & $20.97 \pm 13.91$ & $21.24 \pm 8.54$ & $92.62 \pm 43.54$ \\
Tea-5 & $22.33 \pm 13.93$ & $34.46 \pm 7.17$ & $92.77 \pm 43.54$ \\
Tea-6 & $21.04 \pm 13.66$ & $33.86 \pm 7.04$ & $91.01 \pm 42.75$ \\
Tea-7 & $22.18 \pm 14.73$ & $36.92 \pm 7.60$ & $98.13 \pm 46.10$ \\
Tea-8 & $22.75 \pm 15.02$ & $37.26 \pm 7.74$ & $100.43 \pm 47.03$ \\
Tea-9 & $20.65 \pm 13.90$ & $21.24 \pm 8.54$ & $92.71 \pm 43.54$ \\
Tea-10 & $20.73 \pm 13.42$ & $33.57 \pm 6.92$ & $89.22 \pm 41.98$ \\
Tea-11 & $19.06 \pm 12.94$ & $32.05 \pm 6.67$ & $86.39 \pm 40.53$ \\
Average & $21.21 \pm .04$ & $32.43 \pm 7.48$ & $93.47 \pm 43.94$ \\
\hline
\end{tabular}

The activity concentration of the ${ }^{226} \mathrm{Ra}$ in tea samples ranged from $19.06 \pm 12.94 \mathrm{Bqkg}^{-1}$ to $23.31 \pm 15.33 \mathrm{Bqkg}^{-1}$ with an average value of $21.21 \pm 14.04 \mathrm{Bqkg}^{-1}$. The highest activity concentration of ${ }^{226} \mathrm{Ra}$ was found in sample code Tea- 3 and lowest activity concentration of the ${ }^{226} \mathrm{Ra}$ was found in sample code Tea-11. These values are lower than the allowable average value $35 \mathrm{Bqkg}^{-1}$ (UNSCEAR 2000).

The activity concentration of the ${ }^{232} \mathrm{Th}$ in tea samples ranged from 21.24 $\pm 8.54 \mathrm{Bqkg}^{-1}$ to $37.95 \pm 7.90 \mathrm{Bqkg}^{-1}$ with an average value $31.46 \pm 1.71 \mathrm{Bqkg}^{-1}$. The highest activity concentration of the ${ }^{232} \mathrm{Th}$ was found in sample code Tea- 3 and lowest activity concentration of the ${ }^{232}$ Th was found in sample code Tea-9. Acceptable value of concentration for ${ }^{232} \mathrm{Th}$ is 40
93.47 $\pm 43.94 \mathrm{Bqkg}^{-1}$. The highest activity concentration of the ${ }^{40} \mathrm{~K}$ was found in sample code Tea- 3 and lowest activity concentration of the ${ }^{40} \mathrm{~K}$ was found in sample code Tea-11. The values are less than the allowable value 400 $\mathrm{Bqkg}^{-1}$ (UNSCEAR 2000).

\section{Radiological indices}

The radiological parameters such as indices of radium equivalent activity $\left(\mathrm{Ra}_{\mathrm{eq}}\right)$, absorbed dose rate (D), internal hazard index $\left(\mathrm{H}_{\mathrm{in}}\right)$, external hazard index $\left(\mathrm{H}_{\mathrm{ex}}\right)$ and annual effective dose equivalent $\left(D_{\text {eff }}\right)$ have been measured to estimate the radiological risk due to the presence of ${ }^{226} \mathrm{Ra},{ }^{232} \mathrm{Th}$ and ${ }^{40} \mathrm{~K}$ in the samples. Table 2 depicts the values of $\mathrm{Ra}_{\mathrm{eq}}, \mathrm{D}, \mathrm{H}_{\mathrm{in}} \mathrm{H}_{\mathrm{ex}}$ and $\mathrm{D}_{\text {eff. }}$

The values of radium equivalent activity in tea samples have been found to be varied from 
$58.16 \mathrm{Bqkg}^{-1}$ to $85.44 \mathrm{Bqkg}^{-1}$ with an average of $74.44 \mathrm{Bqkg}^{-1}$ which is far below the internationally accepted value $370 \mathrm{Bqkg}^{-1}$.

The absorbed dose rates due to these radioactive samples that indicate the non-hazardous value for human being. Artificial radionuclide like ${ }^{137} \mathrm{Cs}$ was not found in any samples under present study.

Table 2. The Radium equivalent activity, Absorbed dose rate, Annual effective dose equivalent, External and Internal hazard indices associated with the tea samples

\begin{tabular}{cccccc}
\hline Sample ID & $\mathbf{R}_{\text {eq }}(\mathbf{B q} / \mathbf{k g})$ & $\begin{array}{c}\text { Internal } \\
\text { Hazard } \\
\text { Index }\left(\mathbf{H}_{\text {in }}\right)\end{array}$ & $\begin{array}{c}\text { External } \\
\text { Hazard } \\
\text { Index }\left(\mathbf{H}_{\mathbf{e x}}\right)\end{array}$ & $\begin{array}{c}\text { Absorbed } \\
\text { Dose Rate, } \mathbf{D} \\
\left(\mathbf{n G y h}^{-1}\right)\end{array}$ & $\begin{array}{c}\text { AEDE } \\
\left(\mathbf{D}_{\text {eff }}\right) \\
\left(\boldsymbol{\mu S v y}^{-1}\right)\end{array}$ \\
Tea-1 & 73.92 & 0.25 & 0.20 & 32.82 & 48.33 \\
Tea-2 & 77.91 & 0.27 & 0.21 & 34.59 & 50.94 \\
Tea-4 & 85.44 & 0.29 & 0.23 & 37.95 & 55.89 \\
Tea-5 & 58.47 & 0.21 & 0.16 & 26.38 & 38.85 \\
Tea-6 & 78.75 & 0.27 & 0.21 & 35.00 & 1.54 \\
Tea-7 & 82.47 & 0.26 & 0.21 & 33.97 & 50.02 \\
Tea-8 & 83.76 & 0.28 & 0.22 & 36.64 & 53.96 \\
Tea-9 & 58.16 & 0.29 & 0.23 & 37.20 & 54.79 \\
Tea-10 & 75.61 & 0.21 & 0.16 & 26.24 & 38.64 \\
Tea-11 & 71.54 & 0.24 & 0.20 & 33.57 & 49.44 \\
Average & 74.78 & 0.26 & 0.19 & 31.77 & 46.78 \\
nuclides in tea samples have been found to vary & CONCLUSION & & 49.02
\end{tabular}

from $26.24 \mathrm{nGyh}^{-1}$ to $37.95 \mathrm{nGyh}^{-1}$ with an average value of $33.28 \mathrm{nGyh}^{-1}$. These measured values are less than the world average value 60 $\mathrm{nGyh}^{-1}$.

Annual effective dose equivalent have been calculated from $38.64 \mu \mathrm{Svy}^{-1}$ to $55.89 \mu \mathrm{Svy}^{-1}$ with an average value $49.02 \mu \mathrm{Svy}^{-1}$ respectively which is less than the annual dose limit $1 \mathrm{mSv}$ for the general public according to the Nuclear Safety and Radiation Control (NSRC) Rules1997 of Bangladesh and International Atomic Energy Agency (IAEA) Safety StandardsGeneral Safety Requirements (GSR) Part 3. On the other hand, the values of external and internal hazard indices for different samples varied from 0.16 to 0.23 with the average value of 0.20 and from 0.21 to 0.29 with an average of 0.26 . The values were less than unity in all the
In this study, the radionuclides presented in tea samples consumed in Bangladesh such as ${ }^{226} \mathrm{Ra}$, ${ }^{232} \mathrm{Th}$ and ${ }^{40} \mathrm{~K}$ were identified with average values of $21.21 \pm 14.04 \mathrm{Bqkg}^{-1}, 32.43 \pm 7.48 \mathrm{Bqkg}^{-}$

${ }^{1}$ and $93.47 \pm 43.94 \mathrm{Bqkg}^{-1}$ respectively. Annual effective dose associated with the tea samples have been found from $38.64 \mu \mathrm{Svy}^{-1}$ to 55.89 $\mu \mathrm{Svy}^{-1}$ with an average value $49.02 \mu \mathrm{Svy}^{-1}$ respectively which is less than the effective dose limit $1 \mathrm{mSv}$ for public exposure in a year set by the Nuclear Safety and Radiation Control (NSRC) Rules-1997 of Bangladesh and International Atomic Energy Agency (IAEA) Safety Standards- General Safety Requirements (GSR) Part 3. Values of radium equivalent activity in all samples are less than the permissible maximum value of the radium equivalent activity which is $370 \mathrm{Bqkg}^{-1}$ 
according to UNSCEAR 2000 report. The obtained mean values of internal and external hazard indices for different tea samples are less than unity. No artificial radionuclide was found in any of the tea samples. So, tea consumption in Bangladesh is not hazardous for public health. The data generated in this study will provide baseline radiometric values for natural and artificial radioactivity in tea and help to develop future guidelines in Bangladesh for radiological protection of the population.

\section{ACKNOWLEDGEMENT}

The authors are grateful to the scientists as well as all the staff of Health Physics Division, Atomic Energy Centre Dhaka, Bangladesh Atomic Energy Commission for their kind assistance and for providing laboratory facilities.

\section{REFERENCES}

Ahmed, M. M., S. K. Das, M. A. Haydar, M. M. H. Bhuiyan, M. I. Ali, D. Paul. 2014. Study of Natural Radioactivity and Radiological Hazard of Sand, Sediment, and soil Samples from Inani Beach, Cox's Bazar, Bangladesh, J. of Nuclear and Particle Physics 4(2): 69-78.

Belivermis, M., Kikic, O., Cotuk, Y. and Topcuoglu, S. 2010. The Effect of Physicochemical Properties on Gamma Emitting Natural Radionuclide Levels in the Soil Profile of Istanbul, Environmental Monitoring and Assessment, 163: 15-26.

Beretka, J. and P. J. Mathew. 1985. Natural Radioactivity of Australian Building Materials, Industrial Wastes and By-products. Health Physics; 48: 87-95.
Khatun, R., Saadat, A. H. M., Ahasan, M. M., Akter, S., 2013. Assessment of Natural Radioactivity and Radiation Hazard in Soil Samples of Rajbari District of Bangladesh. 2: 1-8.

Knoll, G. F. 1998. Radiation Detection and Measurement. 3rd edition. John Wiley and Sons, Inc New York.

Miah, A., Miah, M. M., Kamal, M., Chowdhury, M, I., Rahmatullah, M., 2012. Natural Radioactivity and Associated Dose rates in soil Samples of Malnichera Tea Garden in Sylhet District of Bangladesh. J. Phys. G., 2: 147-152.

Pedro, L. F., Martin, M. J., Pablos, F., Gonzalez, A., G., 2001 Differentiation of tea (Camellia sinensis) varieties and their geographical origin according to their metal content. $J$ AgricFoodChem, 49: 4775-4779.

UNSCEAR (2000). United Nations Scientific Committee on the Effects of Atomic Radiation. Sources and effects of ionizing radiation, vol. 1, New York, United Nations Publication.

UNSCEAR 2008. United Nations Scientific Committee on the Effects of Atomic Radiation Sources and Effects of Ionizing Radiation United Nations Scientific Committee on the Effects of Atomic Radiation. United Nations, New York.

(Received revised manuscript on 12 November 2018) 